\title{
Transmission of SARS-CoV-2 in children aged 0 to 19 years in childcare facilities and schools after their reopening in May 2020, Baden-Württemberg, Germany
}

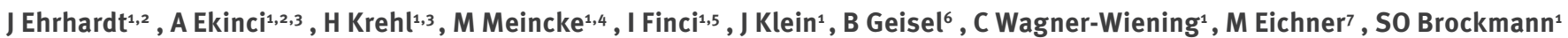

1. Department of Health Protection and Epidemiology, Baden-Wuerttemberg State Health Office, Stuttgart, Germany

2. These authors contributed equally

3. Project Containment Scouts, Federal Office of Administration, Cologne, Germany

4. Postgraduate Training for Applied Epidemiology (PAE), Robert Koch-Institute Berlin, Germany

5. European Programme of Intervention Epidemiology Training (EPIET), Stockholm, Sweden

6. Department of Hygiene and Infection Control, Baden-Wuerttemberg State Health Office, Stuttgart, Germany

7. Institute for Clinical Epidemiology and Applied Biometry, University of Tübingen, Germany

Correspondence: Stefan O. Brockmann (stefan.brockmann@rps.bwl.de)

Ehrhardt I, Ekinci A, Krehl H, Meincke M, Finci I, Klein I, Geisel B, Wagner-Wiening C, Eichner M, Brockmann SO. Transmission of SARS-CoV-2 in children aged

o to 19 years in childcare facilities and schools after their reopening in May 2020, Baden-Württemberg, Germany. Euro Surveill. 2020;25(36):pii=2001587. https:// doi.org/10.2807/1560-7917.ES.2020.25.36.2001587

We investigated data from severe acute respiratory syndrome coronavirus 2 (SARS-CoV-2) infected 0-19 year olds, who attended schools/childcare facilities, to assess their role in SARS-CoV-2 transmission after these establishments' reopening in May 2020 in Baden-Württemberg, Germany. Child-to-child transmission in schools/childcare facilities appeared very uncommon. We anticipate that, with face mask use and frequent ventilation of rooms, transmission rates in schools/childcare facilities would remain low in the next term, even if classes' group sizes were increased.

To gain further understanding on paediatric transmission of severe acute respiratory syndrome coronavirus 2 (SARS-CoV-2) in the school/childcare-facility context, we compiled and analysed data from SARS-CoV-2 infected children (age: 0-19years), who had been to school/childcare facilities, after such establishments reopened in Baden-Württemberg in May 2020.

\section{Reopening of schools/childcare facilities in Baden-Wüirttemberg}

Closure of schools and childcare facilities was part of the German national response and containment strategy of SARS-CoV-2, like in most other European Union countries [1]. In the federal state of Baden-Württemberg in south-west Germany, which has a population of 10.8 million, school and childcare facility closures were mandated on 17 March 2020. From that time, some emergency childcare facilities were nevertheless established for children whose parents both worked in essential services. On 27 April, they were extended to children of persons who could not work from home; for all others, childcare facilities finally reopened on 29 June. Concerning schools, almost 2 months after closing, these reopened in a stepwise manner, beginning on 4 May with the graduating classes of secondary schools, followed on 18 May by the graduating classes of primary schools, and finally, on 15 June, by all remaining classes. The reopening of schools and childcare facilities was accompanied by a series of measures to prevent the spread of SARS-CoV-2 (Table 1 ).

\section{Data source, study period and} epidemiological investigation

To assess the viral transmission role of SARS-CoV-2infected children who attended schools and childcare facilities after their reopening, we searched all notified (i.e. laboratory-confirmed) coronavirus disease (COVID19) cases from the state of Baden-Württemberg. Data on all cases aged 0-19years in the period from 25 May to 5 August 2020 (i.e. from 1 week after school opening in May until 1 week after school closure due to the summer holidays; Figure 1) were compiled.

We contacted the notifying local health offices and reinvestigated school-attendance during the presumed infectious period of these cases, which was according the national standards of the Robert Koch Institute assumed to start 2 days before the onset of symptoms or, in case of an asymptomatic infection, 48 hours before the sampling date of the positive test result [2]. Upon identifying cases, the local health offices had initiated thorough contact investigations in the schools and childcare facilities respectively.

\section{Ethical statement}

This analysis was conducted as part of public health usual practice, and was not conducted for research. Ethics approval was, therefore, not needed. 
TABLE 1

Infection control measures for the prevention of SARS-CoV-2 transmission in schools and childcare facilities in BadenWürttemberg, Germany, May-July 2020

\begin{tabular}{|c|c|c|c|}
\hline Infection control measure & $\begin{array}{l}\text { Childcare } \\
\text { facilities }\end{array}$ & $\begin{array}{l}\text { Primary } \\
\text { school }\end{array}$ & $\begin{array}{c}\text { Secondary } \\
\text { school }^{\mathrm{a}}\end{array}$ \\
\hline Group sizes reduced by $50 \%$ & Yes & Yes & Yes \\
\hline Cleaning of contact surfaces & Yes & Yes & Yes \\
\hline Regular and interim ventilation of rooms & Yes & Yes & Yes \\
\hline Exclusion of sick children & Yes & Yes & Yes \\
\hline Individual hygiene (hand hygiene, cough etiquette) & Yes & Yes & Yes \\
\hline Face mask outside classroom & No & Some & Some \\
\hline Physical distancing between children & No & No & Yes \\
\hline Cancelling singing and use of wind instruments during music lesson & Some & Yes & Yes \\
\hline Cancelling physical education & NA & Yes & Yes \\
\hline
\end{tabular}

NA: not applicable; SARS-CoV-2: severe acute respiratory syndrome coronavirus 2.

a Including vocational school.

White backgrounds indicate measures which will remain unchanged after reopening following the 2020 summer holidays; light blue back-

grounds indicate measures that will be cancelled after the 2020 summer holidays; dark blue backgrounds indicate measures that will be estab-

lished (mask outside classroom) or should be established in the authors' opinion (ventilation and mask in classrooms).

\section{FIGURE 1}

Daily number of notified COVID-19 cases in Baden-Württemberg, by date of reporting, Germany, 25 February-07 August $2020(\mathrm{n}=37,752)$

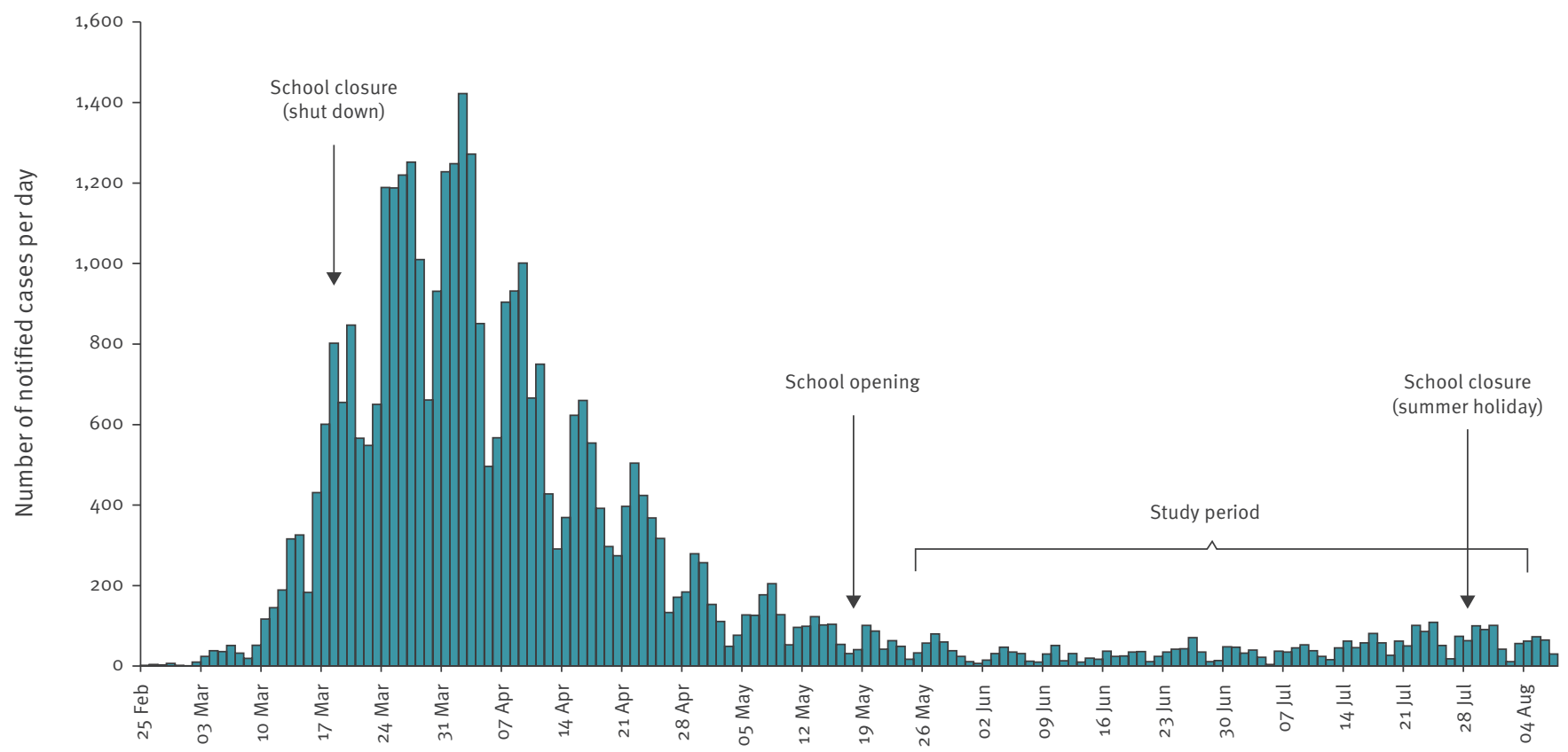

Date in 2020

COVID-19: coronavirus disease.

Arrows show the dates of school closing and opening. The bracket indicates the study period, from 1 week after schools had completely reopened ( 25 May 2020) to 1 week after the beginning of summer holiday (5 August 2020). 


\section{FIGURE 1}

Weekly number of notified SARS-CoV-2 infections in the age group 0-19 years by source of infection, BadenWürttemberg, Germany, 25 May-2 August 2020 (n=453)

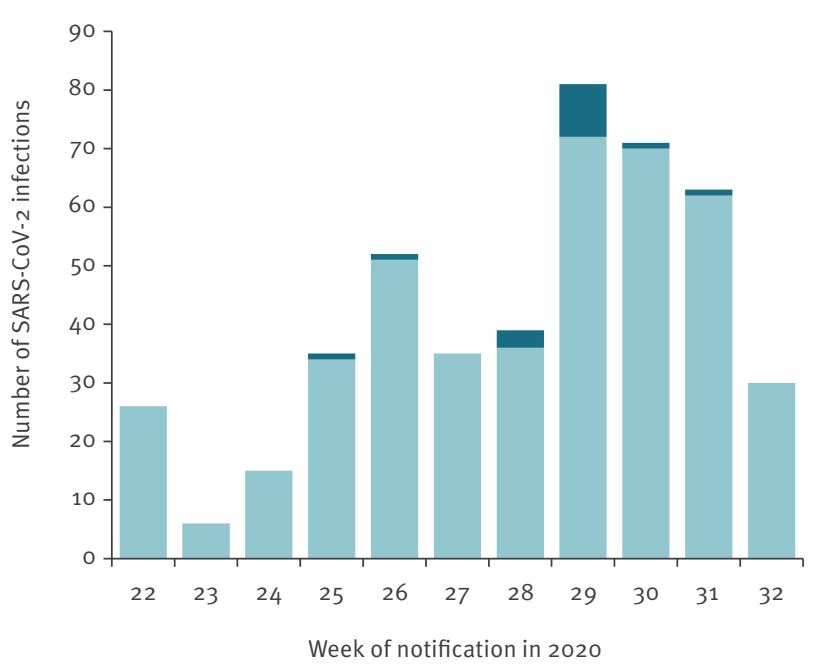

Other source

Infected in school/childcare

SARS-CoV-2: severe acute respiratory syndrome coronavirus 2.

Cases infected in school/childcare are shown in dark blue, cases infected by other sources in light blue.

\section{Cases and transmission events in schools and childcare settings}

In total, 557 cases of age 0-19 years were notified during the study period in Baden-Württemberg $(17.9 \%$ of all 3,104 notified cases) and for 453 (81.3\%) information on school attendance was available; 137 (30\%) of these 453 cases attended school or childcare settings for at least 1 day in their infectious period whereas the remaining 316 were at home during their entire infectious period. More than 2,300 nasopharyngeal swabs were taken from the close contacts (teachers and pupils) of the 137 index cases, and from the close contacts of any secondary cases, if identified. Swabbing usually occurred 3 to 5 days after the index cases' diagnosis. Six of the 137 cases were found to have infected a total of 11 additional pupils (one to three pupils per case; see Figure 2; three in childcare facilities, one in primary school, four in secondary school and three in vocational school), whereas no secondary infections could be detected for the remaining cases despite extensive contact tracing and swabbing of school and childcare-facility contacts. To the best of our knowledge, aside from the 11 secondary cases and another four pupils who were infected by two teachers, all remaining cases with information on school attendance $(n=437)$ were caused by sources outside of school and childcare facilities (Table 2).

Assuming that every one of the 137 index cases spent on average 2 days at school during the infectious period, the 11 secondary cases originated from a cumulative number of 274 infectious days, i.e. one secondary case per roughly 25 infectious school days.
TABLE 2

Source of SARS-CoV-2 infection in persons aged 0-19years, Baden-Württemberg, Germany, 25 May-5 August $2020(\mathrm{n}=453)^{\mathrm{a}}$

\begin{tabular}{|c|c|c|}
\hline Setting/source of infection & $\begin{array}{c}\text { Number of infected } \\
\text { persons }\end{array}$ & Percentage \\
\hline Household & 190 & $41.9 \%$ \\
\hline Parents & 93 & NA \\
\hline Grandparents & 13 & NA \\
\hline Siblings & $7^{\mathrm{b}}$ & $\mathrm{NA}$ \\
\hline Not specified & 77 & $\mathrm{NA}$ \\
\hline Festivity/event & 38 & $8.4 \%$ \\
\hline School/childcare & 15 & $3.3 \%$ \\
\hline By pupil & 11 & $\mathrm{NA}$ \\
\hline By teacher & 4 & $\mathrm{NA}$ \\
\hline Church/community of faith & 14 & $3.1 \%$ \\
\hline Travel associated & 5 & $1.1 \%$ \\
\hline Others & 4 & $0.9 \%$ \\
\hline Unknown or not available $^{\mathrm{d}}$ & 187 & $41.3 \%$ \\
\hline
\end{tabular}

NA: not applicable; SARS-CoV-2: severe acute respiratory syndrome coronavirus 2 .

a Of the 557 children aged 0-19 years who were notified with SARS CoV-2 infection, data on school attendance were available for 453. Information on these 453 children is presented in the table.

b Seven children infected in three intra-household clusters.

c Birthdays and other parties, weddings, funerals.

${ }^{d}$ As close contacts of the cases were thoroughly examined, it is unlikely that cases in the 'unknown' category were infected in childcare facilities, schools or private households.

\section{Discussion and conclusion}

There is an ongoing discussion in the scientific community regarding the role of children in the transmission of SARS-CoV-2. Recently, the percentage of children and adolescents up to 19 years old among all COVID-19 cases in Germany has increased to $25 \%$ [3]. Infected children are more likely to remain asymptomatic or have a mild course of disease and are much less likely than adults to be hospitalised or have fatal outcomes. Thus, their infection may go undetected or undiagnosed. Symptomatic children seem to shed virus in similar quantities as adults and can infect others in a similar way, but it is unknown how infectious asymptomatic children are $[1,4,5]$.

Our investigation suggests that child-to-child transmission in schools and childcare facilities is uncommon and not the primary cause of SARS-CoV-2 infection in children. Based on our estimation there could be one secondary case per roughly 25 infectious school days. This ratio of 1 in 25 might, however, overestimate the transmission risk in schools and childcare facilities, because some of the 104 index cases (i.e. $104=557-453)$ for whom no information on school attendance was available, may also have spent some time in school or in a childcare facility while being infectious, yet without further generating any notified COVID-19 cases. While investigations from Ireland concur with our results [6], a report from Israel showed a large outbreak in apparently over-crowded schools 
where face-mask usage had been discontinued due to a heat wave [7].

The low transmission in schools and childcare facilities found in this current study might be due in part to the infection control measures initiated after school/childcare-facility reopening, yet it is not clear how much the different measures have contributed. In order to gradually return to the regular school and childcare-facility life, larger classes will have to be accepted again. This will require more proximity between pupils. As a countermeasure, strict ventilation of classrooms, not only between lessons but also within, should be implemented [1]. Additionally, face masks should be used in schools, both, inside and outside of classrooms. Based on our current study findings, we anticipate that transmission rates in schools and childcare facilities would remain low under such interventions [8].

\section{Acknowledgements}

This evaluation has become possible by the laborious work of all local health offices in Baden-Württemberg.

We thank the reviewer for many helpful comments and suggestions.

\section{Conflict of interest}

None declared.

\section{Authors' contributions}

$S B, J E, B G, C W$ and $M E$ designed the study. JE, AE, HK, MM, IF, JK, BG and CW contributed to the acquisition of the data. $\mathrm{SB}, \mathrm{ME}, \mathrm{JE}, \mathrm{AE}$ analysed the data. SB, ME, JE, HK and MM interpreted the data. All authors revised the manuscript and approved the final version.

\section{References}

1. European Centre for Disease Control and Prevention (ECDC). ECDC Technical report: COVID-19 in children and the role of school settings in COVID-19 transmission, 6 August 2020. Stockholm: ECDC; 2020. Available from: https://www.ecdc.europa.eu/en/publications-data/ children-and-school-settings-covid-19-transmission

2. Robert Koch Institute (RKI). Kontaktpersonennachverfolgung bei respiratorischen Erkrankungen durch das Coronavirus SARS-CoV-2; Stand: 14.8.2020. [Contact tracing for respiratory diseases caused by the corona virus SARS-CoV-2; Status: August 14, 2020]. Berlin: RKI; 2020. German. Available from: https://www.rki.de/DE/Content/InfAZ/N/Neuartiges Coronavirus/Kontaktperson/Management.html?nn=13490888

3. Robert Koch Institute (RKI). Coronavirus Disease 2019 (COVID-19) Daily Situation Report of the Robert Koch Institute. Berlin: RKI; 18.08.2020. Available from: https:// www.rki.de/DE/Content/InfAZ/N/Neuartiges_Coronavirus/ Situationsberichte/2020-08-18-en.pdf? blob=publicationFile

4. Jones TC, Mühlemann B, Veith T, Biele G, Zuchowski M, Hoffmann J, et al. An analysis of SARS-CoV-2 viral load by patient age. MedRxiv.2020; (Preprint).

5. Yonker LM, Neilan AM, Bartsch Y, Patel AB, Regan J, Arya P, et al. Pediatric SARS-CoV-2: Clinical Presentation, Infectivity, and Immune Responses. J Pediatr. 2020;So022-3476(20)31023-4. https://doi.org/10.1016/j.jpeds.2020.08.037 PMID: 32827525

6. Heavey L, Casey G, Kelly C, Kelly D, McDarby G. No evidence of secondary transmission of COVID-19 from children attending school in Ireland, 2020. Euro Surveill. 2020;25(21):2000903. https://doi.org/10.2807/1560-7917.ES.2020.25.21.2000903 PMID: 32489179

7. Stein-Zamir C, Abramson N, Shoob H, Libal E, Bitan M, Cardash $\mathrm{T}$, et al. A large COVID-19 outbreak in a high school 10 days after schools' reopening, Israel, May 2020. Euro Surveill. 2020;25(29):2001352. https://doi.org/10.2807/1560-7917. ES.2020.25.29.2001352 PMID: 32720636

8. Chu DK, Akl EA, Duda S, Solo K, Yaacoub S, Schünemann HJ, et al. , COVID-19 Systematic Urgent Review Group Effort (SURGE) study authors. Physical distancing, face masks, and eye protection to prevent person-to-person transmission of SARS CoV-2 and COVID-19: a systematic review and meta-analysis. Lancet. 2020;395(10242):1973-87. https://doi.org/10.1016/ So140-6736(20)31142-9 PMID: 32497510

\section{License, supplementary material and copyright}

This is an open-access article distributed under the terms of the Creative Commons Attribution (CC BY 4.0) Licence. You may share and adapt the material, but must give appropriate credit to the source, provide a link to the licence and indicate if changes were made.

Any supplementary material referenced in the article can be found in the online version.

This article is copyright of the authors or their affiliated institutions, 2020. 